\title{
SOBRE A DEFINIÇÃO DE NATUREZA
}

\author{
Lucas Angioni* \\ angioni.lucas@gmail.com
}

RESUMO Pretendo neste artigo discutir a definição de natureza que Aristóteles oferece em Física 192b 20-23, tentando mostrar que tal definição deve ser entendida como uma conjunção de três (não apenas duas) condições: a primeira condição estabelece que a natureza é um tipo de causa; a segunda condição diz respeito à relação entre a natureza e a coisa natural que a tem como princípio e causa; a terceira condição diz respeito à relação entre a natureza e as propriedades que, enquanto causa, ela instila na coisa natural.

Palavras-chave Causalidade, natureza, ontologia, metafísica, hilemorfismo, essencialismo.

ABSTRACT I discuss in this paper Aristotle's definition of nature in Physics 192b 20-23. I intend to prove that this definition has to taken as a set of three (not only two) conditions: the first condition just establishes that nature is a sort of cause; the second condition concerns the relationship between nature and the natural thing that has it as a cause; the third condition concerns the relationship between nature and the properties that natural things have from nature's causality.

Keywords Causality, nature, ontology, metaphysics, hylomorphism, essentialism.

* Professor do Departamento de Filosofia da Unicamp. Recebido em 9/01/2010 e aprovado em 7/03/2010.

KRITERION, Belo Horizonte, nº 122, Dez./2010, p. 521-542. 
I.

No início do livro II de sua Física, em 192b 20-23, Aristóteles define a noção de "natureza" como princípio (ou causa) interna de mudança. Seu objetivo mais imediato consiste em caracterizar a natureza em oposição a outro tipo de princípio de mudança, que é a causalidade técnica. Acredita-se que a definição de natureza estabeleceria apenas dois requisitos, o primeiro dos quais seria uma propriedade compartilhada com a noção de técnica, ao passo que o segundo marcaria a especificidade da natureza. Ambas, natureza e técnica, seriam princípios de mudança, ${ }^{1}$ mas a natureza seria um princípio interno à coisa que sofre a mudança, em contraste com a técnica, que é um princípio externo à coisa que sofre a mudança.

Nesse horizonte, a definição de natureza poderia ser entendida pela conjunção de apenas dois requisitos, os quais poderíamos resumir do seguinte modo:

(1) Natureza é certo princípio ou causa de mudança;

(2) Natureza é o princípio ou causa de mudança que pertence intrinsecamente à coisa que sofre a mudança. ${ }^{2}$

$\mathrm{O}$ critério (1) apenas almeja situar o definiendum em seu gênero e, por isso, não é suficiente para distinguir a característica mais específica da natureza, enquanto distinta da causalidade técnica. Assim, Aristóteles acrescenta o critério (2), para diferenciar a natureza da técnica, sendo esta última um princípio que provêm "de fora", isto é, que não está intrinsecamente dado na própria coisa que sofre a mudança (Cf. Física, 192b 28-31).

No entanto, o caso de um médico que se curasse a si mesmo traria algumas complicações para essa definição de natureza. Em atenção a essas complicações e para especificar mais claramente o modo pelo qual o critério (2) deveria ser entendido, Aristóteles acrescentaria que a natureza é uma causa que pertence à coisa enquanto esta coisa é tomada em si mesma, conforme a descrição relevante. Esse requisito não seria satisfeito no caso do médico que se cura a si mesmo. Nesse caso, a coisa movida, no exemplo de Aristóteles, é o doente que recupera sua saúde: é ele que se submete à mudança engendrado pelo médico, conforme à arte da medicina. Mas, enquanto tal, quem recupe-

1 Não há dúvida de que "kineisthai", na definição de natureza em 192b 21(assim como "kinesis" em 192b 14), deve ser entendido no sentido geral de mudança: qualquer uma das quato classes de metabole reconhecidas em Física 201a 1-9. Tratei do assunto com mais detalhe em Angioni 2009: p. 200, 203.

2 Ver Mansion 1948: p. 99; Ross 1936: 349. A posição de Wieland 1970: p. 317, é mais nuançada: ele parece assumir a interpretação tradicional, mas relata - ainda que não o faça com muita clareza - a diferença entre, por um lado, a relação entre a coisa natural e a natureza (como causa) e, por outro, a relação entre a coisa natural e o movimento que decorre da natureza. 
ra sua saúde não tem, primeiramente e em si mesmo, a capacidade de curar doentes. Trata-se de mera contingência o fato de coincidirem em um mesmo indivíduo as propriedades de ser médico e estar a recuperar sua saúde.

Nesse sentido, considerando-se tais elucidações, a definição de natureza poderia ser entendida do seguinte modo:

(1) Natureza é certo princípio ou causa de mudança;

(2) Natureza é o princípio ou causa de mudança que pertence intrinsecamente à coisa que muda, isto é, que pertence a essa coisa na medida em que ela é tomada em si mesma e não por concomitância. ${ }^{3}$

Essa interpretação funda-se em certa compreensão da sintaxe do texto grego, o qual diz o seguinte:

"hôs ousês tês physeôs archês tinos kai aitias tou kineisthai kai êremein en hôi hyparchei prôtôs kath' hauto kai mê kata symbebêkos" (192b 20-3).

Apesar de divergências de detalhe, quase todos os tradutores e intérpretes parecem ter o mesmo entendimento da sintaxe do texto (a rigor, eles seguem a interpretação consagrada por Simplício) ${ }^{4}$. Eles julgam que:

(a) o advérbio "prôtôs" modifica o verbo "hyparchei";

(b) as locuções adverbiais que se seguem, "kath' hauto kai mê kata symbebêkos", também modificariam o mesmo verbo "hyparchei" e se destinariam a elucidar mais claramente o sentido do advérbio "prôtôs".

(c) A expressão "en hoi" deveria ser entendida como abreviação de "ei toutoi (dativo) en hoi", mas não como abreviação de "touto (nominativo) en hoi", e se destinaria a elucidar que a natureza, como princípio, está nas coisas que a têm primeiramente. ${ }^{5}$

Quanto ao ponto (a), não há dúvida de que ele está correto. No entanto, há uma grave incompreensão no ponto (c), mas não me deterei nele independen-

3 Ver Ross 1936: p. 349.

4 Ver Simplício, in Aristotelis Physicorum Libros Quattuor Priores Commentaria. A rigor, o comentário de Simplício é bem confuso, prolixo e filosoficamente medíocre: (i) em 266.2-4, 7-9, Simplício sugere que "kath' hauto kai mê kata symbebêkos" seria um adendo a "prôtôs"; (ii) em 266.12-14, da primeira impressão de "adendo" ou "elucidação suplementar", Simplício passa a entender as expressões como equivalentes (intersubstituíveis), como se tivessem os mesmos propósitos e os mesmos efeitos: "prôtôs" desaparece, sendo substituída por "kath' hauto kai mê kata symbebêkos"; (iii) em 266.29-30, ele atribui essa interpretação a Alexandre; (iv) em 266.33, ele passa a discutir a necessidade do acréscimo das expressões "prôtôs" e "kath' hauto kai mê kata symbebêkos" e às vezes até vislumbra uma análise bem mais satisfatória (como é a análise de Temístio, enxuta e precisa), como em 267. 11-12, mas (v) em 267.18 volta à análise sugerida acima e, o que é pior, em 267.22 ss., passa a discutir com pormenor a diferença lógica e explanatória entre "prôtôs" e "kath' hauto kai mê kata symbebêkos", discussão que é útil em si mesma, mas conflita com (ii). A rigor, entre os passos (i)-(ii)-(iii) e o passo (v), parece haver total separação, como se Simplício os tivesse escrito independentemente, sem notar o conflito. No final das contas, apesar da utilidade das distinções discutidas em (v), o que prevalece é sua interpretação defendida em (i)-(ii), respaldada em Alexandre em (iii). Análise muito melhor, como veremos, é a de Temístio.

5 Para a expressão cristalina desse ponto (c), ver Ross 1936: 501. 
temente do ponto (b). Do ponto de vista da compreensão do texto grego, julgo, contrariamente à opinião majoritária, que a expressão "en hoi" é abreviação de "touto (nominativo) en hoi", e o pronome oculto "touto" (i) é o sujeito dos infinitivos "kineisthai kai eremein", (ii) refere-se à coisa natural, cujo movimento próprio deve ser explicado pela causalidade natural, (iii) é aquilo a que se aplicam as expressões "kath' hauto kai me kata symbebekos". A sintaxe do texto deve ser compreendida do seguinte modo: "causa" (aitia) pede um complemento (que introduz aquilo de que a causa é causa); ora, tal complemento, introduzido pelo artigo no genitivo "tou", consiste em uma oração infinitiva, "kineisthai kai eremein [touto]", cujo sujeito, "touto", não apenas é qualificado por uma oração relativa ("en hoi hyparchei prôtôs") ${ }^{6}$ que esclarece de que modo a natureza lhe pertence, mas também é o escopo das expressões adverbiais "kath' hauto kai me kata symbebêkos", que elucidam sob qual interpretação semântica do termo "touto" é verdadeira a sentença que introduz o explanandum ("kineisthai kai eremein [touto]").

Considero surpreendente que renomados especialistas tenham tão facilmente se deixado seduzir pelo ponto (c), mas me concentrarei no ponto (b): pretendo mostrar que, se queremos ler em 192b 20-23 uma definição precisa da noção de natureza, devemos entender que as locuções adverbiais " $k a t h$ ' hauto kai mê kata symbebêkos" modificam os verbos "kineisthai kai êremein" e, com isso, introduzem na definição de natureza um terceiro critério relevante (e não apenas uma elucidação do segundo critério). Nessa perspectiva, a noção de natureza deveria ser entendida como uma conjunção progressiva das três seguintes condições:

(1) Natureza é certo princípio ou causa de mudança;

(2) Natureza é um princípio ou causa de mudança que pertence intrinsecamente à coisa que sofre a mudança;

(3) Natureza é princípio ou causa de certa classe de mudanças que ocorrem à coisa à qual pertence primeiramente, a saber, causa das mudanças que ocorrem à coisa natural na medida em que a coisa natural é tomada nela mesma - mas não é causa das mudanças que ocorrem à coisa natural na medida em que ela é tomada por concomitância.

6 Considero desnecessário argumentar em favor da plausibilidade gramatical dessa construção. Esse tipo de construção, no qual o antecedente de um pronome relativo é omitido, é absolutamente trivial no grego (quer antecedente e relativo estejam no mesmo caso ou não, quer estejam sob regime da mesma preposição ou não) e, além do mais, o próprio Ross, que formulou a opção rival (c) contra a qual argumento, admite a plausibilidade de "touto en hoi" e atenua sua proposta com um advérbio de cautela ("en hoi probably = en toutoi (rather than touto) en hoi", p. 501). 
A razão para insistir em uma definição com três condições não é mero preciosismo pedantesco. Tampouco se trata de mera filologia sem interesse filosófico. Como veremos na seção V deste artigo, uma definição com apenas duas condições seria ineficaz para os propósitos de distinguir a natureza como tipo específico de causalidade. Certo tipo de causalidade técnica pode perfeitamente satisfazer apenas as duas primeiras condições - ser uma causa de mudança, ser uma causa de mudança na coisa à qual pertence primeiramente. Nessas circunstâncias, porém, é óbvio que a definição de natureza colapsa em seus objetivos - não define o que tomou como definiendum.

Meu ponto pode ser mais bem elucidado se considerarmos que, para Aristóteles, toda relação de causalidade deve ser analisada em três termos, em última instância. ${ }^{7}$ Qualquer causa é um termo terceiro, que é causa de uma relação entre dois outros termos, a saber, causa de uma relação pela qual tal e tal propriedade está presente em tal e tal sujeito.

Essa estrutura triádica da relação de causalidade reflete-se no esquema da primeira figura da silogística de Aristóteles. Esse ponto pode ser ilustrado pela forma Barbara:

Premissa maior: todo $B$ é $A$;

Premissa menor: todo $C$ é $B$.

Conclusão: todo $C$ é $A$.

A relação entre os termos $C$ e $A$ consiste no explanandum para o qual se deve especificar uma causa. Essa causa é o termo médio $B$; aquilo de que a causa é causa é a propriedade $A$ (extremo maior); por outro lado, aquilo para $o$ que a causa é causa é o sujeito $C$ (extremo menor) no qual está dada a propriedade $A .{ }^{8}$ Aristóteles não mantém sistematicamente essa distinção terminológica entre "aquilo de que a causa é causa" e "aquilo para o que a causa é causa", mas é bem claro que ele mantém sistematicamente, em sua obra, uma concepção de causa como fundamento pelo qual um dado sujeito tem uma dada propriedade. Assim, a razão pela qual o sujeito $C$ tem a propriedade $A$ consiste no fato de ele ter a propriedade mais básica $B$, a qual é fundamento (aition) do qual se segue a propriedade $A$.

Com auxílio desse quadro, posso elucidar melhor o que pretendo ao discutir as três condições presentes na definição de natureza. A condição (1) apenas situa a natureza em seu gênero, dizendo que ela é uma causa. ${ }^{9}$ A condição

7 Essa concepção de causalidade como uma relação triádica é bem clara em vários contextos: Segundos Analíticos 90a 5-10, 98b 5-7 ss., 99a 1-2 ss., 99a 16-18 ss.; Metafísica 1041a 10-b 9. Tratei do assunto com algum detalhe em Angioni 2009: cap. 10.

8 Ver Segundos Analíticos II 17, 99a 16-18.

9 Esse ponto é absolutamente consensual. 
(2) diz respeito à relação entre $C$ e $B$, tal como formulada na premissa menor do silogismo acima explicitado - ou seja, a condição (2) diz respeito à relação entre a coisa natural, $C$ (tomada como aquilo que possui uma causa, ou seja, possui uma propriedade básica que fundamenta outra) e a natureza, $B$ (enquanto causa). A condição (3), por sua vez, diz respeito à relação entre a causa e aquilo que é propriamente seu explanandum completo, a saber, a presença da propriedade $A$ no sujeito $C$. Essa relação, no entanto, é complexa e pode ser descomposta em elementos mais básicos. É essa decomposição que ocorre, exatamente, na estrutura do silogismo de primeira figura. Por um lado, $B$, como causa, é uma propriedade mais básica da qual se segue a propriedade $A-\mathrm{e}$ isso é representado na premissa maior do silogismo. Por outro lado, da conjunção entre essa relação de acarretamento de propriedades (premissa maior) e a atribuição da causa $B$ ao sujeito $C$ (premissa menor), se segue aquilo que se quer explicar: a atribuição da propriedade $A$ ao sujeito $C$.

Essa decomposição da relação de causalidade me permite reformular o ponto. Assim, dizer que a condição (3) diz respeito à relação entre a causa e aquilo que é propriamente seu explanandum completo, a saber, a presença da propriedade $A$ no sujeito $C$, consiste em dizer que a condição (3) diz respeito à relação entre $C \mathrm{e} A$ (sendo $A$ aquilo que se deve explicar) e, consequentemente, diz respeito à relação entre $B$ e $A$ (sendo tal relação a parte mais fundamental do explanans).

Suponha-se, assim que o termo $B$ representa a noção de natureza, o termo $C$, a noção de coisa natural, e o termo $A$, a noção de certo movimento ou repouso, tomada como exemplo paradigmático de propriedade cuja atribuição à coisa natural é suscetível de ser explicada pela causalidade da natureza. Podemos, então, representar essas relações no seguinte esquema silogístico:

Toda natureza causa certo tipo de movimento e repouso.

Todo ente natural tem, intrinsecamente, natureza.

Logo, todo ente natural tem certo tipo de movimento e repouso. ${ }^{10}$

Minha proposta é que a condição (2), referente ao advérbio "prôtôs" ligado ao verbo "hyparchei", se destina a elucidar a premissa menor desse silogismo. Por outro lado, a condição (3), referente à locução adverbial ' kath'

10 Suponho que o ponto que quero esclarecer por meio desse esquema silogístico tenha ficado claro. No entanto, alguns, por formalismo, poderiam objetar que não temos um silogismo válido, pois temos quatro termos, não apenas três: o extremo maior é primeiramente dado como "causar certo tipo de movimento", depois é dado como "ter certo tipo de movimento". Para satisfazer aspirações formalistas e evitar essa objeção, basta reformular nosso silogismo do seguinte modo: "(maior) ter a natureza como causa implica ter tais e tais tipos de movimento; (menor) todo ente natural tem a natureza como causa; (conclusão) logo, todo ente natural tem tais e tais tipos de movimento". A aparente imprecisão nas expressões que usei são autorizadas por aquilo que Aristóteles diz sobre "hyparchein" em Primeiros Analíticos I 36. 
hauto kai me kata symbebekos" ligada aos verbos "kineisthai/eremein", está primeiramente localizada na conclusão desse silogismo e, ao assinalar o tipo de atributo que se constitui como explanandum relevante que deve ser explicado pela causalidade natural, essa locução ao mesmo tempo indica o tipo de relação que deve haver, na premissa maior, entre a natureza (enquanto causa) e certos tipos de movimento e repouso (enquanto propriedades cuja atribuição aos entes naturais deve ser explicada pela natureza). Em última instância, posso resumir o ponto dizendo que a locução adverbial 'kath' hauto kai me kata symbebekos" se destina a elucidar qual é o tipo especifico de movimento (ou repouso) suscetível de ser explicado pela causalidade da natureza.

\section{II.}

De acordo com opinião amplamente aceita, a oposição entre "kath' hauto" e "kata symbebêkos" exprime a oposição entre "essencialmente" e "por acidente". E, quanto à sintaxe original dessas expressões gregas, acredita-se que a expressão "kata symbebêkos" seria uma espécie de operador modal cujo escopo seria uma proposição em seu todo. Assim, quando se afirma que "o médico kata symbebêkos é construtor de casa" ", acredita-se que uma boa análise dessa sentença seria "é contingente que um médico construa casas". Julgo que essa análise, embora não seja incompatível com o que Aristóteles pretende na maioria dos casos, não capta precisamente o que ele quer dizer. Em outras palavras, os resultados de tal análise engendram, em muitos casos, proposições que Aristóteles aceitaria como verdadeiras (como, por exemplo, a proposição "é contingente que um médico construa casas"). Não obstante, tal análise não capta precisamente o modo pelo qual a expressão "kata symbebêkos" funciona no texto de Aristóteles.

Em vários contextos, a oposição entre "kath' hauto" e "kata symbebêkos" consiste em oposição entre modos pelos quais um termo (sujeito ou predicado) de uma dada predicação deve ser tomado, para que a proposição, já suposta como verdadeira, se ateste como verdadeira. ${ }^{12}$ Dado que "kath' hauto" e "hei hauto" são, nesses contextos, usadas como expressões equivalentes entre

11 A rigor, em Física I 8, 191 b 4, Aristóteles afirma que "o médico constrói casa não enquanto médico, mas enquanto construtor", mas em 191b 14-15 ss. torna-se claro que "não enquanto médico" e "enquanto construtor" equivalem a "médico kata symbekekos": o "symbebekos", no caso, é um atributo que acompanha o médico, a saber, "construtor". Para mais detalhes,ver Angioni 2009: p. 172-7.

12 Para outros exemplos dessa oposição entre "kath' hauto" e "kata symbebekos", ver Física 254b 7-12; Segundos Analíticos 74b 5-12; Tópicos 110b 21-25. Essa oposição supõe como dada a verdade das sentenças a que se aplica e introduz distinção relevante para elucidar as relações causais que tornam tais sentenças verdadeiras. Mas desenvolver esse ponto exigiria outro artigo. 
si, ${ }^{13}$ tentarei elucidar a oposição tomando como exemplo o modo pelo qual Aristóteles, em Física I 8, procura resolver a aporia dos eleáticos. O contraste relevante pode ser resumido a duas sentenças:

(a) Médico exerce a medicina (iatros iatreuei);

(b) Médico constrói casa (iatros oikodomei).

Ambas as sentenças são dadas como verdadeiras, e o objetivo de Aristóteles consiste em discernir as condições sob as quais elas são verdadeiras. É bem claro que as condições sob as quais a sentença (a) é verdadeira são bem distintas das condições que tornam (b) verdadeira. Sentenças do tipo (a) são entendidas por Aristóteles como definicionalmente verdadeiras. Isso quer dizer que, para que a sentença (a) seja verdadeira, basta que o termo "médico" seja tomado tão somente em si mesmo, o que, neste contexto, quer dizer: ser tomado enquanto médico, conforme as características que fazem todo médico ser médico, e não conforme as características que, irrelevantes para sua caracterização enquanto médico, fazem um médico ser também outra coisa (por exemplo, musical, construtor de casa, branco, etc.). Consequentemente, sendo verdadeira conforme a mera definição do termo sujeito, a sentença (a) será verdadeira para todos os casos particulares de médico.

Por outro lado, para que a sentença (b) seja verdadeira, não mais basta tomar o termo "médico" tão somente em si mesmo, ou seja, enquanto médico, conforme as características que fazem médico ser, precisamente, médico, e não outra coisa. Se supusermos como verdadeira a sentença (b), ${ }^{14}$ devemos admitir que o termo "médico" não é usado nessa sentença para introduzir as características essenciais que se atribuem universalmente a qualquer médico; devemos admitir que o termo "médico" se reporta a algum indivíduo que, sendo médico, também satisfaz a descrição relevante pela qual se torna verdadeiro dizer que ele constrói casas. Ou seja, a sentença (b), sendo verdadeira, não pode querer dizer outra coisa, senão que "há certo indivíduo, que é médico, e que constrói casas". Para compreender as condições sob as quais a sentença (b) é verdadeira, devemos compreender que o termo "médico", nesse caso, é usado para remeter a um indivíduo que, sendo médico, tem também a característica sob a qual é verdadeiro atribuir-lhe o predicado "constrói casas" (e a tem como symbebêkos).

13 Cf. Segundos Analíticos 73b 28-32.

14 E Aristóteles a supõe como verdadeira. Ou melhor: Aristóteles parece partir da constatação de que sentenças como essa são usadas de modo eficaz na linguagem ordinária, como sendo verdadeiras, e procura descrever as c condições sob as quais elas são verdadeiras. 
$\mathrm{Na}$ expressão original de Aristóteles, se diz que "o médico kata symbebekos constrói casa". Pois bem: a expressão "kata symbebekos", longe de ter por escopo a proposição em seu todo, consiste em uma cláusula semântica que incide sobre o termo-sujeito da sentença e indica sob qual interpretação esse termo deve ser entendido, para que a sentença, já dada como verdadeira, seja verdadeira. Qual é a interpretação a ser dada ao termo "médico", pela cláusula "kata symbebêkos"? O termo "médico" deve ser tomado com uma propriedade (ou um concomitante) que lhe acompanha: nesse caso, a propriedade em questão consiste em ser um indivíduo capaz de construir casas (oikodomos).

Assim, a oposição entre "kath' hauto" e "kata symbebêkos" pode ser entendida como oposição entre modos pelos quais o sujeito de uma predicação deve ser tomado para que a proposição seja verdadeira. Podemos dizer que:

(a) "Médico, em si mesmo, exerce a medicina" (iatros kath' hauto iatreuei, cf. 191b 6, com a variante "hei iatros" em vez de "kath' hauto").

No entanto, não mais poderíamos dizer que "médico, em si mesmo, constrói casa (iatros kath' hauto oikodomei). Pelo contrário, devemos dizer que:

(b) "Médico, por concomitância, constrói casa" (iatros kata symbebêkos oikodomei).

A expressão "kath' hauto" indica que a sentença é verdadeira de acordo com a definição do termo-sujeito. Para que o predicado "exerce a medicina" seja verdadeiro a respeito de "médico", basta tomar o termo "médico" conforme as características que definem sua essência. Daí também decorre que tal predicado será verdadeiro para qualquer caso do sujeito, de modo que podemos afirmar que "todo médico exerce a medicina", pois exercer a medicina é a função pela qual se define o ser médico.

Por outro lado, a expressão "kata symbebêkos" indica que a mera definição do termo sujeito não é suficiente para garantir a verdade da sentença. Para que o predicado "construir casa" seja verdadeiro a respeito de "médico", não podemos tomar o sujeito tão apenas conforme as características que the cabem essencialmente; devemos tomá-lo como uma descrição que remete a um indivíduo que possui, como propriedade concomitante, a propriedade relevante sob a qual o predicado se mostra verdadeiro. Daí se segue que o predicado "construir casas" jamais poderia ser generalizado como verdadeiro para todo e qualquer caso de "médico"; ao contrário, ele é verdadeiro apenas para o caso particular considerado na sentença.

Podemos então generalizar o ponto, abandonando os exemplos particulares com os quais Aristóteles o formulou originalmente. Podemos dizer que as expressões "kath' hauto" e "kata symbebekos" indicam sob quais condições uma dada sentença " $S$ é $P$ " é verdadeira: 
1) “Skath'hauto éP" quer dizer que o predicado $P$ pode ser verdadeiramente atribuído a $S$ de acordo com o sentido definicional de $S$.

2) "S kata symbebêkos é P" quer dizer que o predicado $P$ não pode ser verdadeiramente atribuído a $S$ de acordo com o sentido definicional de $S$, mas é verdadeiramente atribuído a $S$ pelo fato de que $S$ remete, no contexto particular em questão, a algo que tem as propriedades relevantes que o fazem ser $P$.

\section{III.}

Ressalto que essa oposição entre "kath' hauto" e "kata symbebekos" também é aplicada por Aristóteles a enunciados que exprimem relações causais. Isso é relevante para meus propósitos, dado que a definição de natureza a caracteriza justamente como causa de certas mudanças (ou repousos) nos entes naturais. Assim, considere-se a sentença " $A$ é causa de $B$ ". As expressões "kath' hauto" e "kata symbebekos" podem incidir sobre qualquer um dos termos - $A$ ou $B$ - dessa sentença, e indicam sob quais condições a sentença é verdadeira. ${ }^{15}$

Temos, então, dois casos:

(i) “ $A$, kath' hauto, é causa de B":

A expressão "kath' hauto" indica que o enunciado é verdadeiro pela própria definição de ambos os termos. Isso quer dizer que ambos os termos descrevem adequadamente os itens entre os quais se dá a relação causal. Para evidenciar a relação causal, não é preciso examinar as propriedades concomitantes que acompanham as coisas a que se referem os termos " $A$ " e " $B$ ". Por exemplo: "o escultor, em si mesmo, é causa (eficiente) da estátua".

(ii) "A, kata symbebêkos, é causa de $B$ ":

A expressão "kata symbebêkos" indica que tal sentença não é verdadeira pela própria definição de ambos os termos. Ao contrário, para evidenciar a relação causal que tal sentença pretende exprimir, é preciso considerar as propriedades concomitantes que acompanham as coisas a que se referem os termos " $A$ " e " $B$ ". Por exemplo: "Policleto, por concomitância, é causa (eficiente) da estátua", o quer dizer que "Policleto é escultor", sendo que "o escultor, em si mesmo, é causa (eficiente) da estátua". ${ }^{16}$

15 Desenvolvi esse ponto com mais detalhe em Angioni 2009, p. 270-274.

16 O mesmo poderia ser dito no caso do efeito: "o cozinheiro é causa (eficiente) da saúde, por concomitância", porque "o cozinheiro, em si mesmo, é causa (eficiente) da iguaria (ou do prazer gustativo que a iguaria propicia)", e "ocorre que a iguaria é saudável". Cf. Metafísica 1027a 3-5; Física 195b 6-9. 
Podemos dizer, portanto, que sentenças do tipo (i), que exprimem uma "causa per se", são sentenças nas quais o termo $A$ é descrito de tal modo, que é condição suficiente para que seja verdadeiro o predicado, "ser causa de $B$ ". É preciso cuidado, no entanto, para não engendrar confusão quanto à tese que propomos. Não estou a propor que "causas per se" são causas suficientes para gerar o efeito de que são causas. Meu ponto diz respeito apenas às condições para que seja verdadeiro, a respeito de um dado sujeito $A$, o predicado "ser causa de $B$ " - independentemente dos adjetivos que se possam acrescentar ao termo "causa". Podemos classificar uma causa sob um dos quatro tipos de causa que Aristóteles reconhece: causas materiais, causais eficientes, causas formais e causas finais. Podemos também atribuir a uma dada causa a propriedade de ser suficiente, ou necessária, ou adequada, ou próxima, ou remota etc. Mas meu ponto situa-se em um nível de generalidade que prescinde de qualquer qualificação ulterior que se possa acrescentar à noção de causa. Minha proposta diz respeito apenas às condições semânticas sob as quais um dado termo " $A$ " pode receber verdadeiramente o predicado "ser causa de $B$ ".

Suponha-se o enunciado "o sangue é causa (material) do animal". Não estou a propor que o fato de o sangue ser causa per se do animal implique que o sangue seja causa suficiente para a geração de um animal. Quero dizer apenas que, supondo-se a fórmula " $x$ é causa (material) de um animal", $x$ será causa per se desde que sua definição for suficiente para tornar a fórmula verdadeira, sem exigir uma análise semântica ulterior. Assim, o sangue, por sua própria definição, é tal que é verdadeiro atribuir-lhe a propriedade de ser causa (material) do animal. Isso quer dizer que o sangue, em si mesmo - isto é, conforme a definição de sua essência - , é condição suficiente para a verdade da sentença em que lhe atribuímos o predicado "ser causa do animal".

O mesmo vale para os efeitos, ou aquilo de que as causas são causas. ${ }^{17}$ Podemos exprimir esse ponto de vários modos. De fato, podemos adotar como modelo o seguinte esquema sentencial:

(i) “ $B$, kath' hauto, é efeito de $A$ " (que é a contraparte complementar do esquema “ $A$, kath' hauto, é causa de $B$ ").

Ou então podemos adotar o seguinte modelo:

(i') " $B$, kath' hauto, é causado por $A$ ".

A variação entre (i) e (i') parece-me irrelevante e, por mera comodidade, adotarei a primeira opção. Em ambos os esquemas, porém, a expressão "kath' hauto" indica que o enunciado é verdadeiro pela própria definição de ambos 
os termos. Para evidenciar a relação causal entre $A$ e $B$, não é preciso examinar as propriedades concomitantes que acompanham as coisas a que se referem os termos " $A$ " e " $B$ ". Por exemplo: "a estátua, em si mesma, é efeito (ou produto) do escultor".

Por outro lado, considere-se o esquema sentencial:

(ii) " $B$, kata symbebêkos, é efeito de $A$ ":

A expressão "kata symbebêkos" indica que tal sentença não é verdadeira pela própria definição de cada um dos termos. Para evidenciar a relação causal que essa sentença pretende exprimir, deve-se considerar as propriedades concomitantes que acompanham as coisas a que se referem os termos " $A$ " e " $B$ ". Por exemplo: "o saudável, por concomitância, é efeito do cozinheiro", o que quer dizer que "a iguaria, que é, em si mesma, efeito do cozinheiro, é saudável".

\section{IV.}

Volto, nesta seção, a examinar a definição de natureza em seus elementos básicos. Supomos que toda definição deve dar conta de certos fatos básicos, ou características básicas, de seu definiendum. Um dos fatos básicos a respeito da noção de natureza é que ela envolve uma relação causal entre um objeto natural (termo $C$, no esquema silogístico da seção I) e certo tipo de mudança que ocorre nesse objeto natural (termo $A$, no referido esquema silogístico). Esse tipo de fato pode ser expresso na seguinte fórmula geral: " $B$ causa a mudança $A$ em $C$ ", por exemplo: "o escultor causa tal e tal refiguração no bronze". O mesmo fato pode ser expresso numa fórmula complementar, que apenas focaliza o mesmo fenômeno por outro ângulo: " $C$ sofre a mudança $A$ em virtude de $B$ ", por exemplo: "o bronze adquire tal e tal configuração em virtude do escultor".

Consideremos esse segundo tipo de enunciado, para examinar a relevância da condição (3) na definição de natureza. Como dissemos, a condição (3) diz respeito à relação entre a natureza, como causa $(B)$, e seu explanandum apropriado, que é a ocorrência regular de certo tipo de mudança nos entes naturais. Consequentemente, a condição (3) permite especificar os tipos de mudança que, atribuídos aos entes naturais, são suscetíveis de serem explicados pela causalidade natural (isto é, os tipos de mudança que constituem, a rigor, explananda apropriados ao domínio da ciência da natureza). A condição (3) permite elucidar, portanto, os tipos de movimentos que podem figurar na conclusão do esquema silogístico proposto na seção I.

Ora, a conclusão desse esquema silogístico relata justamente a relação entre um dado objeto natural (termo $C$ ) e uma propriedade suscetível de ser 
explicada pela natureza. Para melhor focalizar essa relação, tomemos como modelo uma forma simplificada do esquema sentencial há pouco proposto:

- "o objeto natural $C$ sofre a mudança $A$ ".

Ora, podemos classificar os enunciados desse tipo em duas classes. Por um lado, temos os enunciados que são verdadeiros pela própria definição do sujeito $\mathrm{C}$, tomado em si mesmo. Por outro, temos os enunciados que são verdadeiros apenas se o sujeito $C$ for tomado por concomitância, isto é, se for tomado de acordo com alguma propriedade ulterior que não está contida em sua definição. A essas duas classes de enunciado, correspondem duas classes de causas, aptas a tomar o lugar de $B$.

Como vimos, dizer que é verdadeiro o enunciado " $C$, em si mesmo, sofre a mudança $A$ " consiste em dizer que $C$, conforme à definição que caracteriza o que ele é essencialmente em si mesmo, é condição suficiente para que o predicado "sofrer a mudança $A$ " lhe seja atribuído com verdade. Por outro lado, dizer que é verdadeiro o enunciado " $C$, por concomitância, sofre a mudança $A$ " consiste em dizer que $C$, conforme à definição que caracteriza o que ele é essencialmente em si mesmo, não é condição suficiente para que o predicado "sofrer a mudança $A$ " se lhe possa atribuir verdadeiramente. Neste caso, a verdade da sentença é garantida apenas na medida em que $C$ for tomado de acordo com outra propriedade, que não pertence à sua definição, mas está implícita no contexto em que se usa o enunciado " $C$ sofre a mudança $A$ ".

Nessa perspectiva, torna-se claro qual seria a motivação filosófica para dizer que as expressões "kath' hauto" e "kata symbebêkos, em 192b 22-23, estão sintaticamente conectadas com os verbos "kineisthai kai êremein" e se destinam a especificar os tipos de mudança e repouso que podem ser atribuídos aos entes naturais enquanto naturais - e que constituem, portanto, explananda apropriados às ciências da natureza, suscetíveis de explicação pela causalidade natural. Mas antes de insistir na motivação filsófica, mostrarei, brevemente, que vários outros textos de Aristóteles também apresentam boas evidências para tomar as expressões "kath' hauto" e "kata symbebekos" com os verbos "kineisthai" e "êremein".

Na discussão sobre o conceito de lugar, no livro IV da Física, Aristóteles diz o seguinte:

"Por um lado, algo é 'movido efetivamente' em si mesmo; por outro, algo é 'movido efetivamente' por concomitância. É 'movido efetivamente' por concomitância aquilo que, em si mesmo, é suscetível de ser movido (por exemplo, as partes do corpo, o prego no navio), assim como aquilo que não é suscetível de ser movido, mas que sempre é 'movido' por concomitância, por exemplo, a brancura e o conhecimento: de fato, estas coisas mudam de lugar porque aquilo em que se encontram muda de lugar" (211a 17-23). 
Essa passagem soa bem obscura, pelo jargão utilizado, mas é bem claro que o objetivo de Aristóteles consiste em determinar condições de aplicabilidade do predicado "kinoumenon", "movido" - tendo em vista que tal predicado implicará, necessariamente, o predicado "estar em um lugar", visto que o movimento pressupõe o lugar (cf. 211a 12-4). Nessa perspectiva, Aristóteles observa que o predicado "kinoumenon" pode ser usado de dois modos: ele pode ser entendido como equivalente a "efetivamente movido" ("kinoumenon energeiai", 211a 17-18), ou como equivalente a "suscetível de ser movido" ("endechomenon kineisthai", 211a 19). Mas o que nos importa, no presente contexto, é ver como essa distinção vem emaranhada com outra precisamente a distinção que mais nos interessa, entre "movido kath' hauto" e "movido kata symbebekos".

Aristóteles diz que o predicado "movido" (kinoumenon), ou "efetivamente movido" (kinoumenon energeiai), aplica-se a certos objetos apenas por concomitância. De acordo com os esquemas que propusemos nas seções anteriores, isso quer dizer que temos duas situações:

(i) " $C$, em si mesmo, é efetivamente movido $(A)$;

(ii) " $C$, por concomitância, é efetivamente movido $(A)$.

No entanto, o próprio caso (ii) é complexo e requer distinção ulterior.

(ii $\left.{ }^{1}\right)$ Por um lado, há objetos que, embora possam, em outras circunstâncias, receber o predicado "efetivamente movido" em si mesmos, não o recebem, em dada circunstância, em si mesmos, mas apenas em virtude de uma propriedade concomitante.

$\left(\mathrm{ii}^{2}\right)$ Por outro, há objetos que jamais poderiam receber o predicado "efetivamente movido" em si mesmos; sempre que tais objetos recebem tal predicado, eles o recebem em virtude de uma propriedade concomitante.

$\mathrm{O}$ caso $\left(\mathrm{ii}^{1}\right)$ pode ser ilustrado por um prego em uma dada embarcação, o qual, embora esteja imóvel em si mesmo, é movido na medida em que a embarcação se desloca. Ora, o prego, na medida em que é um objeto material, é suscetível de ser movido, por ação de outra coisa. A noção de objeto material, mediatamente presente em sua definição, garante que o prego seja, em si mesmo, suscetível de ser movido e, em certas circunstâncias, seja efetivamente movido em si mesmo.

Já o caso ( $\mathrm{ii}^{2}$ ) pode ser ilustrado por uma propriedade como a brancura, que não é entendida como um objeto material suscetível ao movimento. ${ }^{18}$ Não

18 De modo análogo ao caso do predicado "movido", dizemos que "a água é incolor" e que "o som é incolor". No primeiro caso, dizemos que não tem cor um objeto que, naturalmente, satisfaz os requisitos necessários para ter cor (pois tem uma superfície corpórea, etc.), ao passo que, no segundo caso, 
sendo um objeto material, a brancura é tal que, por sua definição, não se segue, nem imediata nem mediatamente, que ela seja suscetível ao movimento. Não obstante, dado que a brancura é uma propriedade que está em corpos, e dado que corpos são objetos materiais suscetíveis ao movimento, a brancura é, por concomitância (por sua relação com um dado corpo) movida, em dada circunstância particular.

Em suma, Aristóteles afirma que o predicado "ser movido" (ou "mudar de lugar") é atribuído a pregos por concomitância, quando ocorre a conjunção dos seguintes fatos: os pregos estão no navio, e o navio se move ou muda de lugar. De modo similar, o predicado "ser movido" (ou "mudar de lugar") é atribuído à brancura por concomitância, quando ocorre a conjunção dos seguintes fatos: a brancura está neste corpo, e este corpo se move ou muda de lugar. Ainda que a brancura não seja um ente apto a receber, naturalmente, o predicado "muda de lugar", ela o recebe em virtude de uma relação "concomitante" com outra coisa, que, de fato, se move em si mesma. ${ }^{19}$

Evidência suplementar advém também de Física IV 5, 212b 7-13. Neste caso, trata-se de determinar as condições de aplicabilidade do predicado "estar no lugar" (en topôi), ou "estar em algum lugar" (pou). Aristóteles afirma que todo corpo, em si mesmo, está em algum lugar, ao passo que a alma (bem como o céu) está em algum lugar apenas por concomitância. Essa observação nos interessa porque o predicado "ser suscetível de movimento" (kineton) é tomado como condição suficiente para inferir a aplicabilidade do predicado "estar no lugar". Assim, como prova de que algumas coisas, em si mesmas, estão no lugar, Aristóteles afirma que "todo corpo, em si mesmo, é suscetível de movimento em algum lugar (kinêton pou), ou por deslocamento, ou por crescimento" (212b 7-8).

No livro II da Física, ao introduzir a definição de natureza, o interesse de Aristóteles não se volta à aplicabilidade geral do predicado "kinêton". Mais estritamente, o propósito de Aristóteles consiste em especificar os tipos de mudança que podem ser atribuídos aos entes naturais enquanto naturais e que, consequentemente, consistem em explananda apropriados ao domínio

dizemos que o objeto em questão não se conta entre aqueles que satisfazem os requisitos necessários para ter uma cor qualquer.

19 Este último caso é similar ao caso da alma (De Anima I 4 408a 30-34 ss.): a alma, em si mesma, não é suscetível de receber o predicado "mover-se" (nem o predicado "estar em repouso"). No entanto, podese dizer que a alma, por concomitância, se move - como abreviação da conjunção entre "a alma está no corpo" e "o corpo se move". Aristóteles diria que a alma, assim como a brancura e o conhecimento, "ou pephyke kineisthai". Por outro lado, o prego, embora não tenha um princípio intrínseco pelo qual auto-determine seu próprio movimento, é tal que "pephyke kineisthai", ainda que só venha a ser movido, efetivamente, em virtude de uma causa externa. 
da ciência da natureza, que só podem ser explicados pela causalidade natural. Visto que entes naturais são naturais porque têm a natureza como princípio (cf. 192b 32-3), são justamente esses tipos de mudança que deverão ser reportados à causalidade da natureza. Aristóteles pretende especificar os tipos de mudança cuja atribuição aos entes naturais pode ser tida como verdadeira pela própria definição dos entes naturais. Tal definição, que caracteriza o ente natural enquanto ente natural, é condição suficiente para garantir a verdade da atribuição desses tipos de mudança, embora ainda seja requisitada uma causa para explicar a razão dessa atribuição. Podemos dizer que uma planta qualquer (uma samambaia, por exemplo) cresce. Igualmente, podemos dizer que tal samambaia vai de Campinas para Belo Horizonte, transportada num veículo. No entanto, embora possamos dizer que:

- "esta samambaia, em si mesma (enquanto ente natural), cresce", não podemos dizer que:

- "esta samambaia, em si mesma (enquanto ente natural), vai de Campinas para Belo Horizonte".

Para que atribuamos à samambaia o movimento de Campinas para Belo Horizonte, é preciso considerar outras características que lhe são concomitantes, e que lhe cabem unicamente na medida em que ela é uma samambaia singular, a saber: a característica de estar em um certo veículo, o qual vai de Campinas para Belo Horizonte. Devemos dizer, então, que:

- "esta samambaia, por concomitância, vai de Campinas para Belo Horizonte".

Tal sentença é um modo compactado de dizer que "esta samambaia está no veículo $V$, e o veículo $V$ vai de Campinas para Belo Horizonte".

Obviamente, a natureza não é causa do transporte da samambaia de Campinas para Belo Horizonte, mas é causa do crescimento da samambaia. Esse argumento mostra, portanto, que as expressões "em si mesmo" e "por concomitância", na definição de natureza, estão conectadas ao verbo "sofrer mudança" (kineisthai). ${ }^{20}$

20 Considere-se ainda a seguinte lista de passagens, nas quais as expressões adverbiais "kath' hauto" e/ou "kata symbebêkos" aplicam-se ao verbo "kineisthai" ou verbos equivalentes: 224a 21-34; 224b 22-27; 225a 24; 225b 13; 226a 19-23; 240b 8-9, 19-20; 241b 38; 242a 43-4; 243b 18-19; 245b 4-5; 248a 9; 249b 12-13; 254b 7-8; 255b 27; 256b 4-7; 257b 21, 33; 259b 18, 24. 


\section{V.}

Voltemos ao texto em que Aristóteles procura definir a noção de natureza. Procurarei mostrar que, se for tomado conforme à interpretação usual, tal texto implicará em paradoxos fatais, que Aristóteles jamais aceitaria. Eis a definição, na interpretação tradicional:

"a natureza é certo princípio ou causa, $x$, pela qual se move ou repousa aquela coisa, $y$, a que primeiramente - isto é, em si mesmo e não por concomitância $-x$ pertence" (192b 20-2).

Conforme já disse, a interpretação tradicional julga que essa definição opera apenas com dois critérios. Sendo o critério (1) genérico e incontroverso, convém concentrar a atenção no critério (2), segundo o qual uma causa $B$ é natureza se satisfizer a seguinte condição:

(2) $B$ é um princípio ou causa de mudança que pertence intrinsecamente à coisa que muda, $C$, isto é, pertence à coisa $C$ em si mesma e não por concomitância.

No entanto, se a definição de natureza terminasse nessa cláusula, Aristóteles não poderia evitar a consequência paradoxal de que a medicina seria natureza, assim como o médico, em seu procedimento de cura, procederia de acordo com uma causalidade natural. De acordo com os termos de Aristóteles, podemos formular os fatos do seguinte modo: o médico, pelo seu conhecimento medicinal, produz a saúde em organismos doentes. Mas considere-se o caso em que um médico se cura a si mesmo. Neste caso, o explanandum seria a presença da propriedade ter saúde (ou ter recobrado a saúde) no sujeito médico. Médico seria o termo $C$, no esquema silogístico introduzido na seção I deste artigo; a saúde (ou recuperação da saúde) seria o termo $A$, a propriedade cuja presença em $C$ deve ser explicada por uma casa; finalmente, a arte da medicina seria o termo $B$, a causa que explica a presença da propriedade $A$ no sujeito $C$. Apenas no intuito de trazer à luz as relações predicativas mais básicas envolvidas na relação de causalidade, formulo o seguinte esquema silogístico: ${ }^{21}$

A arte da medicina é causa da (recuperação da) saúde;

O médico, primeiramente, isto é, em si mesmo e não por concomitância, possui a arte da medicina.

O médico recupera a saúde. 
Ora, não há como evitar, nessa intepretação, o resultado de que a medicina, por satisfazer a condição (2), se tornaria natureza.

No entanto, a sequência imediata do texto mostra que Aristóteles está bem precavido contra essa colapso da definição recém-proposta para a noção de natureza. Aristóteles diz o seguinte:

“digo 'não por concomitância' porque alguém, sendo médico, poderia tornar-se causa de sua própria saúde, mas não é por recuperar a saúde que ele tem a arte medicinal, mas apenas sucede por concomitância que o mesmo homem é médico e está recuperando a saúde; por isso, às vezes eles estão separados um do outro" (192b 23-27).

Aristóteles deixa bem claro que quer introduzir, mediante a cláusula "em si mesmo e não por concomitância", uma diferenciação entre os respectivos modos pelos quais o médico relaciona-se à propriedade de ter a arte da medicina e à propriedade de recuperar a saúde. Formulemos o esquema silogístico em sua forma crua, apenas com a relação entre os três termos: ${ }^{22}$

A arte da medicina $(B)$ - recuperação da saúde $(A)$;

O médico $(C)$ - a arte da medicina $(B)$.

O médico $(C)$ - recuperação da saúde $(A)$.

Ora, na definição de natureza, a oração relativa "naquilo a que a natureza pertence primeiramente" afirma de modo explícito que a relação entre $C$ e $B$ é intrínseca e primitiva: $C$ possui $B$ primeiramente - por sua própria essência. Mas a cláusula "em si mesmo e não por concomitância" é acrescentada para elucidar a relação entre $C$ e $A$ e para evitar a consequência desastrosa de que seria natureza a arte medicinal de um médico que se curasse a si mesmo. Aristóteles diz, explicitamente, que a relação entre "médico" e "recuperar a saúde" é uma relação de concomitância (192b 25-27). Apenas ocorre, em dada circunstância, haver uma identidade extensional entre o médico e o doente que recupera a saúde, mas o predicado "recuperar a saúde" (hygiazetai) não decorre do termo "médico" tomado em si mesmo - tais termos, "recuperar a saúde" e "médico" estão separados entre si em várias circunstâncias.

Assim, a definição de natureza exige o critério (3), ou, para formular o ponto mais precisamente, exige a conjunção dos critérios (2) e (3), os quais dizem que, para uma causa $B$ ser natureza, devem ser intrínsecas não apenas ar elação da causa $B$ com o sujeito $C$ que a possui, mas também a relação da

22 "De forma crua" quer dizer o seguinte: sem se preocupar em detalhar as expressões que garantiriam a validade do silogismo. Aristóteles várias vezes se vale desse expediente (cf. Segundos Analíticos 93a 30 ss.), usando o verbo "hyparchei" como uma espécie de coringa para introduzir relações lógicosintáticas cuja tradução na linguagem comum seria mais espinhosa. Aristóteles até mesmo justifica esse procedimento, do ponto de vista metodológico, em Primeiros Analíticos I 36. 
propriedade $A$ com sujeito $C$ que a possui. ${ }^{23}$ No caso do médico que se cura a si mesmo, de nada valeria, para supostamente garantir o referido paradoxo, substituir o termo "médico" pelo termo "convalescido" (hygiazomenon, 192b 26), como se disséssemos:

A arte da medicina $(B)$ - recuperação da saúde $(A)$;

O convalescido $(C)$ - a arte da medicina $(B)$.

O convalescido $(C)$ - recuperação da saúde $(A)$.

Ora, nesta nova versão do esquema triádico da causalidade, a clásula (3) seria satisfeita, pois o convalecido, em si mesmo e não por concomitância, recebe o predicado "recuperar a saúde", e o movimento tomado como explanandum poderia ser descrito como um movimento intrínseco à coisa movida. No entanto, a cláusula (2) não seria satisfeita, pois não é em si mesmo (nem primeiramente) que o convalescido tem a arte da medicina. Ele tem a arte da medicina enquanto é médico, e apenas ocorre, circunstancialmente, que o mesmo fulano que é médico é também um convalescido.

É atenção a este último caso - no qual apenas a condição (3) é satisfeita, sem a satisfação conjunta da condição (2) - que Aristóteles prossegue:

"Semelhantemente para as coisas que são produzidas: nenhuma delas tem em si mesma o princípio da produção, mas algumas o têm em outras coisas e de fora" (192b 27-29).

As coisas produzidas, no contexto em questão, equivalem ao termo $C$ (pois são dadas em contraste com as coisas naturais): Aristóteles ressalta que elas não têm em si mesmas a causa pela qual sofrem a modificação que é relatada pelo termo $A$ no esquema triádico da causalidade. Ou seja: elas não satisfazem a condição (2). E o objetivo de Aristóteles consiste em ressaltar que o caso do convalescido que, por concomitância, é um médico que se curou a si mesmo, equivale ao caso dos produtos da técnica: a condição (2) não é satisfeita. ${ }^{24}$

23 Temístio (in Aristotelis Physica Paraphrasis), percebe o ponto com muito mais clareza que Simplício: "o médico adoecido e que se cura a si mesmo tem em si mesmo, primeiramente, o princípio eficiente, isto é, a técnica, mas não é em si mesmo que ele recupera a saúde (ou sofre tal mudança): ele recupera a saúde enquanto ocorre por concomitância (symbebêke) que o médico e o doente são o mesmo [fulano]" (36.13-17). Não obstante, é de modo bem confuso que Temístio tentara aplicar o mesmo ponto ao caso do navio movido pelo piloto (36.5-12): ele argumenta que não são intrínsecas nem a relação do navio com o piloto nem a relação do navio com o movimento causado pelo piloto. Temístio parece julgar haver perfeita analogia entre seus dois exemplos, mas isso não me parece ser o caso.

$24 \mathrm{Em}$ alguns casos pertencentes à técnica, seria possível mostrar que a condição (3) é satisfeita ao mesmo tempo em que a condição (2) não o é. Seja $C$ flauta, seja $A$ produção de certos sons agradáveis propícios a banquetes (ou outra descrição qualquer, conforme à imaginação de cada um), seja $B$ a arte de tocar flautas: por um lado, seria verdadeiro dizer que a flauta, em si mesma, por sua própria definição, tem a função de produzir tais e tais sons agradáveis propícios a banquetes; por outro, jamais seria verdadeiro 
Esse fato induziu em erro vários leitores desatentos, que julgaram que o foco da própria expressão "kath' hauto kai mê kata symbebekos" em 192b 22-23 seria também a condição (2), isto é, a relação entre a causa e a coisa que possui a causa, ou a relação entre os termos $B$ e $C$. No entanto, o ponto de Aristóteles é que ambas as condições, (2) e (3), devem ser satisfeitas conjuntamente. Em outras palavras: devem ser intrínsecas não apenas as relações entre objetos naturais $(C)$ e natureza $(B)$, mas também as relações entre objetos naturais $(C)$ e os tipos específicos de mudança $(A)$ que devem ser explicados pela natureza. ${ }^{25}$

Assim, a tradução adequada da definição de natureza seria, antes, a seguinte:

"natureza é certo princípio ou causa pela qual aquilo em que primeiramente se encontra muda ou repousa em si mesmo e não por concomitância" (192b 20-3).

Essa tradução permite ver claramente o que é relevante. Ela compartilha com traduções alternativas o mérito de exprimir que a natureza, bem como toda causa, envolve uma relação triádica (a causa é causa pela qual uma propriedade está presente em um dado sujeito). Mas, além disso, essa tradução tem vantagens suplementares, em comparação com as traduções usuais: ela mostra que a definição de natureza envolve três critérios, e que os dois critérios especificamente relevantes são inseparáveis um do outro - tanto que o

dizer que a flauta, em si mesma (sem o flautista), tem a arte de tocar flautas, que é a causa adequada pela qual se produz sons agradáveis propícios a banquetes.

25 Considerar a definição de natureza como uma conjunção dessas três condições traz ainda uma grande vantagem. Uma insistência enfática na segunda condição, sem a adição da terceira (nos moldes da interpretação tradicional), pode ter consequências indesejadas. O requisito de que a causa do movimento deve pertencer à coisa natural "primeiramente, isto é, em si mesma" pode ser interpretado como exigência de que a coisa natural seja causa de seus movimentos em si mesma, por sua própria essência, e daí se pode passar à tese de que apenas a essência do ente natural é causa de movimentos naturais, com exclusão de qualquer motor externo (pois de nenhum motor externo pode-se dizer que "o ente natural o tem, em si mesmo"). No entanto, esta última tese não é consistente com outras que Aristóteles certamente admite. Nenhum animal é em si mesmo causa suficiente de seus movimentos, pois todo movimento animal depende de um desejo, que por sua vez depende de um objeto externo. A definição de natureza parece sugerir que todo ente natural é auto-movente, em um sentido muito rigoroso. Esse é o paradoxo que motivou o artigo seminal de David Furley, "Self-Movers". Esse paradoxo deve ser resolvido pela conjunção de diversos pontos (e julgo que a solução de Furley 1994: p. 13-14, está bem encaminhada), mas é certo que a definição de natureza pelas três condições que propomos contribui para eliminar pela raiz uma das fontes do paradoxo: em nossa interpretação, a expressão "em si mesmo e não por concomitância" não se destina a enfatizar que a essência dos seres naturais poderia contar, sozinha, como causa suficiente dos movimentos naturais. Aristóteles não está assim tão preocupado em enfatizar que o princípio do movimento deve ser interno e essencial etc. É certo que o princípio deve ser interno e essencial, mas a adição da cláusula "em si mesmo e não por concomitância", longe de pretender enfatizar a essencialidade da relação entre coisa natural e princípio de movimento a ponto de excluir a contribuição de qualquer motor externo, tem por escopo a relação entre a coisa natural e o movimento que lhe é atribuído. 
segundo é expresso, na sintaxe do grego, como oração relativa que qualifica o sujeito da sentença infinitiva que, introduzindo o complemento de "causa", introduz o terceiro critério. ${ }^{26}$ Como resultado do entrelaçamento desses dois critérios, temos uma definição de natureza na qual se exige que sejam intrínsecas as relações que o objeto natural $(C)$ tem, por um lado, com sua causa $(B)$, por outro, com a propriedade explananda, $(A)$. É somente assim que se pode cumprir o objetivo de Aristóteles: captar a especificidade da natureza, como causalidade distinta da técnica.

\section{Referências}

1. Edições do texto de Aristóteles:

BEKKER, E. [1961]. Aristotelis Opera, editio altera Olof Gigon, Berlin: Walter De Gruyter.

ROSS, D. [1936]. Aristotle's Physics, a revised text with introduction and commentary, Oxford: Clarendon Press, 1936.

\section{Traduções, traduções comentadas:}

ANGIONI, Lucas. [2009]. Física I e II. Campinas: Editora da Unicamp. BOERI, Marcelo. [1993]. Física, Buenos Aires: Editorial Biblos.

CARTERON, Henri. [1986]. La Physique, texte établi et traduit (2 vols.), Paris: Les Belles Lettres, (1 $1^{\mathrm{a}}$ ed.1931).

CHARLTON, William. [1992]. Aristotle's Physics - Books I and II. Oxford: Clarendon Press $\left(1^{\text {a }}\right.$. ed. 1970).

COUGHLIN, G. [2005]. Aristotle - Physics or Natural Hearing, South Bend: St. Augustine's Press.

HARDIE \& GAYE. [1924]. Physics, in Ross, D. (edd.) The Complete Works of Aristotle, Oxford: Oxford University Press, \& in Barnes, J. (ed.) The Complete Works of Aristotle, The Revised Oxford Translation, Princeton: Princeton University Press. Princeton: Princeton University Press.

PELLEGRIN, Pierre. [1993]. Physique, Paris: GF Flammarion.

WATERFIELD, Robin [1996]. Aristotle's Physics, Oxfod: Oxford University Press.

26 Como disse na seção I, ao comentar a tese sintática (c) da intepretação tradicional, considero surpreendente o comentário de Ross 1936: p. 501: "en hoi probably = en toutoi (rather than touto) en hoi". Se Ross estivesse correto, nem sequer teríamos no texto aquilo que descrevi como "sentença infinitiva" que introduz o explanandum do qual a natureza é "princípio ou causa". No entanto, "en hoi" é abreviação de "touto en hoi", sendo que "touto" (i) é o sujeito dos infinitivos "kineisthai kai eremein", (ii) introduz o termo "C", que representa a coisa natural, no esquema triádico da causalidade, (iii) é aquilo a que se aplicam as expressões "kath' hauto kai me kata symbebekos", entendidas do modo como propus neste artigo (como cláusulas que indicam sob qual interpretação semântica do termo-sujeito a sentença é verdadeira). 
WICKSTEED, P. M. (trad.) \& CORNFORD, F. M. (coment.). [1957] Physics,, London: Loeb Classical Library.

3. Comentadores gregos:

SIMPLICIO, in: Aristotelis Physicorum Libros Quattuor Priores Commentaria, ed. Herman Diels, in: Commentaria in Aristotelem Graeca, vol.IX, Berlin: Walter de Gruyter, 1882.

TEMISTIO, in: Aristotelis Physica Paraphrasis, ed. Maximillian Wallies, in: Commentaria in Aristotelem Graeca, vol. V, Berlin: Walter de Gruyter, 1900.

\section{Outros:}

FURLEY, David. [1994]. "Self-Movers", in Gill, M.L, \& Lennox, J. (edd.), Selfmotion from Aristotle to Newton, Princeton: Princeton University Press, p. 3-14.

MANSION, Augustin. [1945]. Introduction à la physique aristotélicienne, 2éme édition revue et augmentée, Louvain, Institut Supérieur de Philosophie.

WIELAND, Wolfgang. [1970]. La Fisica di Aristotele, trad. de Carlo Gentili, Bologna: Societá Editrice Il Mulino. 